\title{
Myths of the Baltic Sea eutrophication
}

\section{Motivation}

The applied science cycle, from description of the phenomenon to cause-effect explanations to scenario modelling to managerial recommendations, can be distorted at any of these stages, especially when natural scientists are wandering too far away from their "ivory towers" into socio-economic and political considerations. Although studies of the Baltic Sea eutrophication have matured on the path through the entire cycle from concerns of the early 1970s to the Baltic Sea Action Plan (BSAP) of nowadays, there are still some confusions and misinterpretations that can misdirect future studies and mitigation measures. The following gentle reminders and warnings are illustrated with and supported by results derived from both empirical data ${ }^{1}$ and mathematical models. ${ }^{2,3}$

\section{Ultimate considerations}

There are several inherent properties of the Baltic Region that must always be accounted for in studies and management: natural and anthropogenic North-South and East-West gradients in the drainage basin and marine ecosystems, including limiting nutrients and productivity; compensatory potential of the interconnectivity between the Baltic Sea sub-basins; coastal-offshore interactions with its filtering and transforming capacity, depending on local morphometry; long nutrient residence times and high buffer capacity, determining slow response to the best efforts (Figure 1). Ignorant neglects or intentional disregards of these properties make management inefficient or even harmful.
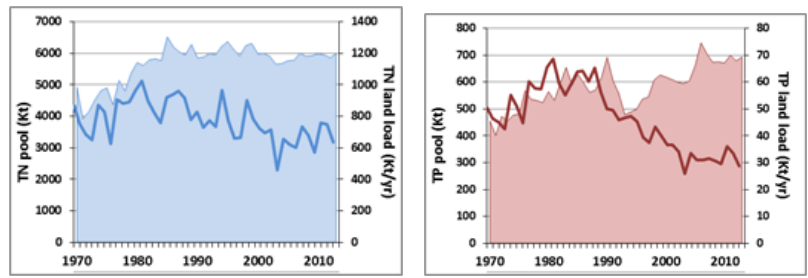

Figure I Dynamics of nitrogen (A) and phosphorus (B) pools (areas) and loads (curves) in the entire Baltic Sea.

\section{Vicious circle}

Inorganic nitrogen removal due to denitrification and release of accumulated phosphate from the anoxic bottoms result in the Redfield excess of inorganic phosphorus that forces dinitrogen into biotic cycling via nitrogen-fixing cyanobacteria, thus increasing primary production, sedimentation and decomposition of organic matter, which, in turn, leads to further expansion of hypoxic zone with increased denitrification and DIP release (Figure 2). Shrinking of hypoxic zone after sporadic Major Baltic Inflows of saline oxygen-replete waters causes opposite changes in the $\mathrm{N}$ and $\mathrm{P}$ pools, but nowadays the improved oxygen conditions do not last long. Besides of such harmful cyanobacteria bloom effects as recreational deterioration and toxicity, this vicious circle 4 counteracts nitrogen load reductions by nitrogen fixation and damages cod reproduction by expanding hypoxia.
Volume 7 Issue 2 - 2018

\section{Oleg P Savchuk}

Baltic Nest Institute, Stockholm University Baltic Sea Centre, Sweden

Correspondence: Oleg P Savchuk, Baltic Nest Institute, Stockholm University Baltic Sea Centre, Sweden Email oleg.savchuk@su.se

Received: March 22, 2018 | Published: March 29, 2018

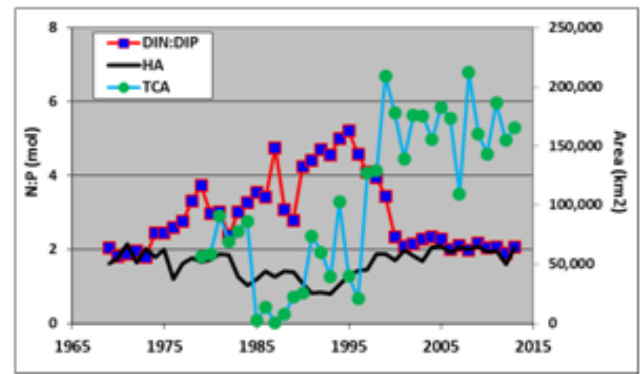

Figure 2 Dynamics of hypoxic area (HA), DIN:DIP ratio computed from 3D DIN and DIP fields, and total area of cyanobacterial accumulations ${ }^{7}$ in the Baltic Proper.

\section{Indicators, indices and integrated assessments}

Objective societal demands and subjective fashion trends result in a blooming development of indicators of variable composition, combining together data and perceptions from variety of disciplines. The evident traps waylaying implementation of this approach include a) uncertainty and subjectivity in prescription of both reference conditions and acceptable deviations, b) inclusion of regionally and locally unimportant indicators for the sake of unification, and c) spatial and temporal inhomogeneity ignored by integrated assessments (Figure 3).

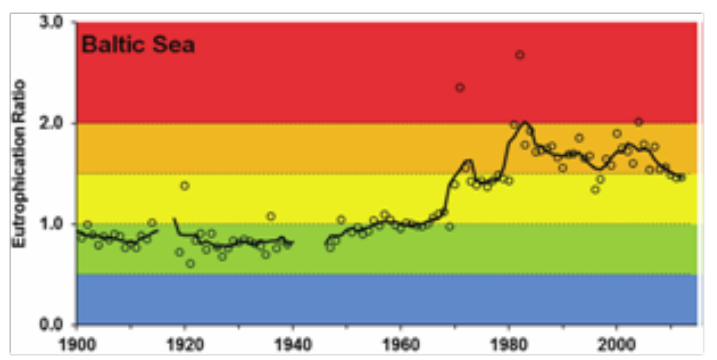

Figure 3 Integrated assessment of the Baltic Sea eutrophication, combining 621 individual classifications. $^{8}$ 
While developing the Baltic Health Index, it is important to avoid some pitfalls of the Ocean Health Index, from a replacement of the "healthy ecosystem" concept as capability to maintain ecosystem's natural structure and function against pressures ${ }^{5}$ with anthropocentric concept of sustaining benefits from ecosystem goods, services, and stewardships; to mixing together both interrelated (non-independent) and sometimes geographically irrelevant indicators.

\section{When science meets management}

Then politics beats science. A few recent Baltic examples include: demand for simultaneous reduction of both $\mathrm{N}$ and $\mathrm{P}$ land loads in BSAP (Figure 4); HELCOM's intention to achieve a Good Environmental Status for the Baltic Sea by $2020 / 21^{6}$ but see Figure 5 for time scales, disregard of nutrient exchange with the Baltic Sea and Skagerrak in the Danish Action Plans for the Aquatic Environment that delayed improvement in open waters of the Danish Straits and Kattegat, comparing to expectations.

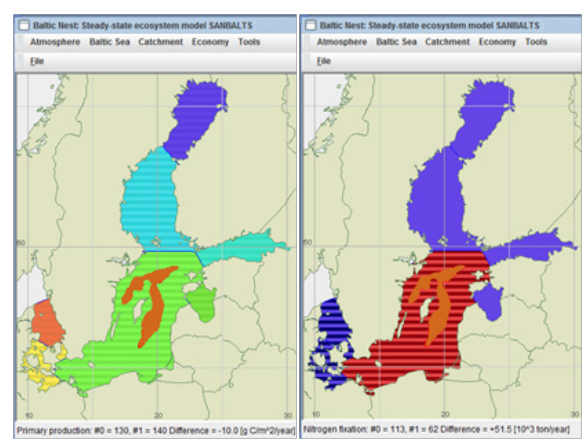

Figure 4 Differences in primary production $\left(A, g \mathrm{C} \mathrm{m}^{-2} \mathrm{yr}^{-1}\right)$ and nitrogen fixation $\left(B, 10^{3} \mathrm{t} \mathrm{N} \mathrm{yr}^{-1}\right)$ in the Baltic Sea sub-basins between scenarios with both $\mathrm{N}$ and $\mathrm{P}$ reductions ( $\# 0$ ) and only $\mathrm{P}$ reductions $(\mathrm{\# I}$ ), amount of reduction corresponds to BSAP. Comparing to case \#0, in case \#I primary production is slightly higher ( 140 instead of $130 \mathrm{~g} \mathrm{C} \mathrm{m}^{-2} \mathrm{yr}^{-1}$ ) but nitrogen fixation is substantially less (62 instead of $11310^{3} \mathrm{t} \mathrm{N} \mathrm{yr}$ ).

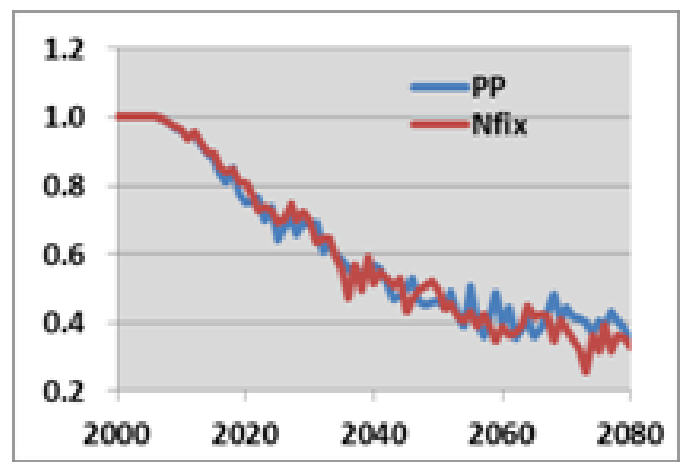

Figure 5 Relative reductions of primary production and nitrogen fixation in BALTSEM scenario simulation where only $P$ reductions were made according to BSAP.

\section{Burning questions}

A few questions could be arisen from above considerations as a contribution to ongoing studies and discussions: a) Are we going to tolerate current cyanobacteria blooms and hypoxia for decades, waiting for large scale effects of expensive nutrient load reductions?

b) Could we try weakening the vicious circling by removing part of accumulated phosphorus with geoengineering measures?

c) Are the Baltic cod existence and fishery important enough to search for a balance between cod food supply and cod reproduction impairment, both generated by cyanobacteria?

d) Is it expedient and possible to develop the Baltic Health Index as being more ecosystems protective rather than commercially exploitive?

\section{Funding details}

The Baltic Nest Institute is supported by the Swedish Agency for Marine and Water Management through their grant 1:11 - Measures for marine and water environment".

\section{Conflict of interests}

Author declares that there is no conflict of interest

\section{Acknowledgments}

None.

\section{References}

1. Savchuk OP. Large-scale dynamics of hypoxia in the Baltic Sea. In Yakushev EV editors. Chemical Structure of Pelagic Redox Interfaces. Observation and Modeling. Berlin Heidelberg: Springer; 2010. p. $137-$ 160 .

2. Savchuk OP, Wulff F. Modeling the Baltic Sea eutrophication in a decision support system. Ambio. 2007;36(2-3):141-148.

3. Savchuk OP, Gustafsson BG, Müller-Karulis B. BALTSEM - a marine model for decision support within the Baltic Sea Region. Baltic Nest Institute Techn. Rep. Ser. 7; 55 p.

4. Vahtera E, Conley DJ, Gustafsson BG, et al. Internal ecosystem feedbacks enhance nitrogen-fixing cyanobacteria blooms and complicate management in the Baltic Sea. Ambio. 2007;36(2-3):186-194.

5. Costanza R, Mageau M. What is a healthy ecosystem? Aquatic Ecology. 1999;33(1):105-115.

6. Backer H, Leppänen JM, Brusendorff AC, et al. HELCOM Baltic Sea Action Plan-A regional programme of measures for the marine environment based on the Ecosystem Approach. Mar Poll Bull. 2010;60(5):642-9.

7. Kahru M, Elmgren R. Multi-decadal time series of satellite-detected accumulations of cyanobacteria in the Baltic Sea. Biogeosciences. 2014;11:3619-3633.

8. Andersen JH, Carstensen J, Conley DJ, et al. Long-term temporal and spatial trends in eutrophication status of the Baltic Sea. Biol Rev. 2015. 